\title{
The SPARC water vapor assessment II: intercomparison of satellite and ground-based microwave measurements
}

Gerald E. Nedoluha ${ }^{1}$, Michael Kiefer ${ }^{2}$, Stefan Lossow ${ }^{2}$, R. Michael Gomez ${ }^{1}$, Niklaus Kämpfer ${ }^{3}$, Martin Lainer ${ }^{3}$, Peter Forkman $^{4}$, Ole Martin Christensen ${ }^{4}$, Jung Jin Oh ${ }^{5}$, Paul Hartogh ${ }^{6}$, John Anderson $^{7}$, Klaus Bramstedt ${ }^{8}$, Bianca M. Dinelli ${ }^{9}$, Maya Garcia-Comas ${ }^{10}$, Mark Hervig ${ }^{11}$, Donal Murtagh ${ }^{4}$, Piera Raspollini ${ }^{12}$, William G. Read $^{13}$, Karen Rosenlof ${ }^{14}$, Gabriele P. Stiller ${ }^{2}$, and Kaley A. Walker ${ }^{15}$

${ }^{1}$ Remote Sensing Division, Naval Research Laboratory, Washington, DC, USA

${ }^{2}$ Karlsruhe Institute of Technology, Institute of Meteorology and Climate Research, Karlsruhe, Germany

${ }^{3}$ Institute of Applied Physics, University of Bern, Bern, Switzerland

${ }^{4}$ Onsala Space Observatory, Department of Radio and Space Science, Chalmers University of Technology, Onsala, Sweden

${ }^{5}$ Sookmyung Women's University, Seoul, South Korea

${ }^{6}$ Max Planck Institute for Solar System Research, Göttingen, Germany

${ }^{7}$ Hampton University, Hampton, Virginia, USA

${ }^{8}$ University of Bremen, Institute of Environmental Physics, Bremen, Germany

${ }^{9}$ Istituto di Scienze dell'Atmosfera e del Clima del Consiglio Nazionale delle Ricerche, Bologna, Italy

${ }^{10}$ Instituto de Astrofisica de Andalucia, CSIC, Granada, Spain

${ }^{11}$ GATS Inc., Driggs, Idaho, USA

${ }^{12}$ Istituto di Fisica Applicata "Nello Carrara" (IFAC) del Consiglio Nazionale delle Ricerche (CNR), Florence, Italy

${ }^{13}$ Jet Propulsion Laboratory, California Institute of Technology, Pasadena, California, USA

${ }^{14}$ University of Colorado, Atmospheric Chemistry Observations \& Modeling Laboratory, Boulder, Colorado, USA

${ }^{15}$ University of Toronto, Department of Physics, Toronto, Ontario, Canada

Correspondence to: Gerald E. Nedoluha (nedoluha@ nrl.navy.mil)

Received: 22 June 2017 - Discussion started: 20 July 2017

Revised: 12 October 2017 - Accepted: 27 October 2017 - Published: 6 December 2017

\begin{abstract}
As part of the second SPARC (Stratospheretroposphere Processes And their Role in Climate) water vapor assessment (WAVAS-II), we present measurements taken from or coincident with seven sites from which ground-based microwave instruments measure water vapor in the middle atmosphere. Six of the ground-based instruments are part of the Network for the Detection of Atmospheric Composition Change (NDACC) and provide datasets that can be used for drift and trend assessment. We compare measurements from these ground-based instruments with satellite datasets that have provided retrievals of water vapor in the lower mesosphere over extended periods since 1996.

We first compare biases between the satellite and groundbased instruments from the upper stratosphere to the upper mesosphere. We then show a number of time series comparisons at $0.46 \mathrm{hPa}$, a level that is sensitive to changes in
\end{abstract}

$\mathrm{H}_{2} \mathrm{O}$ and $\mathrm{CH}_{4}$ entering the stratosphere but, because almost all $\mathrm{CH}_{4}$ has been oxidized, is relatively insensitive to dynamical variations. Interannual variations and drifts are investigated with respect to both the Aura Microwave Limb Sounder (MLS; from 2004 onwards) and each instrument's climatological mean. We find that the variation in the interannual difference in the mean $\mathrm{H}_{2} \mathrm{O}$ measured by any two instruments is typically $\sim 1 \%$. Most of the datasets start in or after 2004 and show annual increases in $\mathrm{H}_{2} \mathrm{O}$ of $0-1 \% \mathrm{yr}^{-1}$. In particular, MLS shows a trend of between $0.5 \% \mathrm{yr}^{-1}$ and $0.7 \% \mathrm{yr}^{-1}$ at the comparison sites. However, the two longest measurement datasets used here, with measurements back to 1996, show much smaller trends of $+0.1 \% \mathrm{yr}^{-1}$ (at Mauna Loa, Hawaii) and $-0.1 \% \mathrm{yr}^{-1}$ (at Lauder, New Zealand). 


\section{Introduction}

Since the early 1990s ground-based microwave (GBMW) instruments have been measuring profiles of water vapor in the middle atmosphere for the detection of long-term change. These ground-based measurements were used in the mid-1990s for satellite intercomparison studies with instruments on the Upper Atmosphere Research Satellite (UARS) and with shuttle-borne instruments during the Atmospheric Laboratory for Application and Science (ATLAS) missions (Nedoluha et al., 1997). Longer-term comparisons were made with measurements from the HALOE instrument (e.g., Nedoluha et al., 2003), and several GBMW instruments were included in the first SPARC water vapor assessment (Kley et al., 2000). A survey of water vapor intercomparisons through 2010 is given by Hocke et al. (2013). More recently, there have been multiyear comparisons between GBMW instruments and Aura MLS and MIPAS (Nedoluha et al., 2013a).

The retrieval of water vapor from GBMW instruments makes use of high-spectral-resolution measurements of emissions near the $22.235 \mathrm{GHz}$ rotational transition of water vapor. The retrieval of water vapor profiles as a function of altitude (or pressure) from the measured spectrum relies upon the sensitivity of the emission at each altitude to pressure broadening. These measurements are taken nearly continuously and, depending primarily upon the altitude to which the retrieval is desired, generally require from several hours to a week of measurement integration. Retrievals are physically possible from the stratosphere to the upper mesosphere (the latter requiring the longest integration periods); however, long-term stability is difficult to maintain below the upper stratosphere because of the difficulty of maintaining a stable instrumental spectral baseline. The optimal retrieval levels for long-term ground-based measurements are therefore in the lower mesosphere.

While all of the ground-based measurements shown here are with instruments measuring at $22.235 \mathrm{GHz}$, the measurements come from different groups, each of which have developed and deployed their own instruments. Each group has its own retrieval code, but all of them make use of the optimal estimation technique (Rodgers, 1976). A detailed explanation of the general retrieval technique and its application to microwave radiometry is given in Kämpfer et al. (2013).

We will first present profile comparisons between satellite and GBMW instruments at a number of sites based upon averages of coincident measurements. We will then take advantage of the fact that ground-based instruments provide the longest available datasets of $\mathrm{H}_{2} \mathrm{O}$ from the upper stratosphere to the upper mesosphere and are therefore especially useful for studies of the stability of satellite measurements in these regions over extended periods of several years. We will then make use of these ground-based measurements to assess the stability of the instruments making these measurements, both satellite and ground-based, and to assess the long-term variations in $\mathrm{H}_{2} \mathrm{O}$.

\section{The measurement datasets}

In this study we show water vapor measurements at seven sites where GBMW instruments have been deployed. For these sites we show measurements from the ground-based instruments and from satellite instruments that make measurements near those ground-based sites. For the six sites for which we have datasets covering at least 4 years we will show time series and investigate temporal variations.

\subsection{The ground-based microwave radiometer datasets}

We will present measurements from seven GBMW instruments. Six of these instruments are part of the Network for the Detection of Atmospheric Composition Change (NDACC) and provide datasets that can be used for drift and trend assessment. Although there is a stronger water vapor emission line at $183 \mathrm{GHz}$ that could be used for observations under dry conditions from high-altitude sites, this emission line is too optically thick to be useful for most locations. Hence, all of these instruments observe the $22 \mathrm{GHz}$ emission line, which allows nearly continuous observation from most sites.

The $22 \mathrm{GHz}$ radiometer at Onsala Space Observatory $\left(57^{\circ} \mathrm{N}, 12^{\circ} \mathrm{E}\right)$ was built and is operated by Chalmers University of Technology in Gothenburg (Forkman et al., 2003). The data are available since 2002 and cover the vertical range $\sim 45-80 \mathrm{~km}$ with a measurement response (Connor et al., 1991) of $>0.75$ (i.e., the a priori contribution to the retrieval is <0.25). The receiver consists of a heterodyne receiver based on an uncooled high electron mobility transistor (HEMT) preamplifier, while the back end is based upon a digital FFT (fast Fourier transform) spectrometer with a bandwidth of $200 \mathrm{MHz}$ over 16000 channels.

The MIddle Atmospheric WAter vapor RAdiometer (MIAWARA) was built in 2002 at the Institute of Applied Physics (University of Bern) and has been continuously operating on the roof of the building for Atmospheric Remote Sensing in Zimmerwald close to Bern $\left(46.7^{\circ} \mathrm{N}, 7^{\circ} \mathrm{E}\right)$ since September 2006. The vertical resolution of the instrument varies between $11 \mathrm{~km}$ in the stratosphere and $14 \mathrm{~km}$ in the mesosphere. A former measurement range from approximately $7-0.1 \mathrm{hPa}$ (Deuber et al., 2005) was extended to roughly $10-0.02 \mathrm{hPa}$ with instrumental upgrades in spring 2007. An acousto-optical spectrometer (AOS) was replaced by a digital FFT spectrometer, which improved the spectral resolution from 600 to $61 \mathrm{kHz}$.

The Seoul WAter vapor RAdiometer (SWARA) was developed, like MIAWARA, at the Institute of Applied Physics at the University of Bern and has been operational since October 2006 at the Sookmyung Women's University of Seoul $\left(37.3^{\circ} \mathrm{N}, 126^{\circ} \mathrm{E}\right)$ in South Korea (De Wachter et al., 2011). SWARA is in principle a copy of MIAWARA and the same specifications apply. However, as the wings of the spectrum are affected by baseline ripples, the retrieval bandwidth is 
limited to $50 \mathrm{MHz}$, and the measurement response (Connor et al., 1991) is $<0.60$ at altitudes below $\sim 38 \mathrm{~km}(\sim 4 \mathrm{hPa})$.

There are currently three Water Vapor Millimeterwave Spectrometer (WVMS) instruments collecting sciencequality data (a fourth WVMS instrument is currently being used to help develop a new feedhorn). The instruments were developed and built at the Naval Research Laboratory with funding from NASA and are operating at Table Mountain, California $\left(34^{\circ} \mathrm{N}, 242^{\circ} \mathrm{E}\right)$, Mauna Loa, Hawaii $\left(19.5^{\circ} \mathrm{N}\right.$, $\left.204^{\circ} \mathrm{E}\right)$, and Lauder, New Zealand $\left(45^{\circ} \mathrm{S}, 170^{\circ} \mathrm{E}\right)$. Early WVMS measurements from Table Mountain are described in Nedoluha et al. (1995), and the evolution of the WVMS systems is described in Gomez et al. (2012). The original instruments at each of these sites have all been replaced by fourth-generation instruments.

Given the small number of GBMW instruments, the difficulty of moving them and ensuring consistency in the measurements, and the absence of any other ground-based technique that could be used as a traveling standard, the standard method of minimizing disruptions to GBMW time series is to compare with a well-established satellite instrument before and after any major change. While this clearly invalidates the GBMW measurements as an independent standard during the period being used to ensure consistency, the major changes to GBMW instruments used in this study are sufficiently infrequent that they do not present an obstacle to multiyear assessments.

Much of the development work on the fourth-generation instruments was done at the JPL Table Mountain site, and the WVMS4 has now been taking science-quality measurements since 2010. A previous system (WVMS2) operated at this site from 1992 until 1997 and measured increasing water vapor in the early 1990s (Nedoluha et al., 1998); however, these measurements will not be shown here. Measurements at Mauna Loa were taken by the WVMS3 system starting in March 1996. The new WVMS6 system at Mauna Loa has been taking measurements since 2011. Similarly at Lauder, the WVMS1 system that had been taking measurements since November 1992 was replaced with the WVMS7 instrument in November 2011. Here we will only use data from Lauder back to the beginning of 1996. While the new instruments use FFTs and measure over a spectral width of $500 \mathrm{MHz}$, the retrievals for this study only make use of the same $60 \mathrm{MHz}$ spectral width used by the older instruments. The wider spectral bandwidth does provide profile information down to the mid-stratosphere, but we have found that the optimization of our retrieval over a larger spectral width can, given imperfectly characterized instrumental baseline changes, adversely affect the consistency of our mesospheric retrievals.

The cWASPAM (cooled Wasserdampf- und Spurengasmessungen in der Atmosphäre mit Mikrowellen) instrument (Hallgren and Hartogh, 2012) has performed observations at ALOMAR (Arctic Lidar Observatory for Middle Atmosphere Research; $69^{\circ} \mathrm{N}, 16^{\circ} \mathrm{E}$ ) in Northern Norway since the summer of 2008. The data included here cover 2008 to 2011. It replaced an older instrument that took measurements at the same location since 1995 (Hartogh and Jarchow, 1995). The instrument was developed by the Max Planck Institute for Solar System Research (now located in Göttingen) and is characterized by high sensitivity. This was achieved by cooling the horn antenna and the hot load (including the amplifier and cold load). The signal detection is performed by two chirp transform spectrometers analyzing both the vertical and horizontal polarization of the signal. The spectrometers have a bandwidth of $40 \mathrm{MHz}$, which is divided into 4096 channels with an effective resolution of $10 \mathrm{kHz}$. Overall this instrument allows us to obtain water vapor information from $\sim 40$ to $85 \mathrm{~km}$.

The measurements from Onsala, Bern, Seoul, Mauna Loa, and Lauder were all compared with Aura MLS in Haefele et al. (2009). Comparisons were made between 0.03 and $3 \mathrm{hPa}$, with the comparisons clearly degrading below $1 \mathrm{hPa}$. For the case of the Seoul measurements the seasonal comparisons were only performed at 0.01 and $0.03 \mathrm{hPa}$. Only the Mauna Loa and Lauder measurements performed well in the upper stratosphere (Haefele et al., 2009). There have since been efforts to extend the useful lower altitude of some of these measurements (Nedoluha et al., 2011; Lainer et al., 2015)

\subsection{Satellite datasets}

We make use of only satellite datasets that provide information in the lower mesosphere, that were operational for a period since 1996, and for which there are coincidences with at least one of the seven ground-based measurement sites. This leaves us with measurements from ACE-FTS, HALOE, MIPAS, Aura MLS, SCIAMACHY, SMR, and SOFIE. In many cases we will show results from multiple retrievals from these instruments. For ACE-FTS we show the two most recent retrieval sets (v2.2 and v3.5; Boone et al., 2005; 2013). For Aura MLS we show only v4.2 retrievals (https://mls.jpl. nasa.gov/data/v4-2_data_quality_document.pdf), since v3.3 retrievals are almost imperceptibly different on the figures. The HALOE comparisons are with the v19 retrieval set, and we will restrict ourselves here to measurements since 1996. For SCIAMACHY we show the solar occultation optimal estimation method (OEM) retrievals, which are sensitive in the upper stratosphere and mesosphere. For SMR we show retrievals from the $489 \mathrm{GHz}$ and strong $557 \mathrm{GHz}$ bands, which are both sensitive to $\mathrm{H}_{2} \mathrm{O}$ in this region of the atmosphere. Both the $489 \mathrm{GHz}$ and the $557 \mathrm{GHz}$ SMR observations have been available since late 2001 and there are typically four measurement days monthly. The $557 \mathrm{GHz}$ SMR observations (Lossow et al., 2007) do not cover the stratosphere and are therefore not included in any of the other SPARC water vapor assessment studies.

From 2002 to 2004 MIPAS operated in a single highspectral-resolution mode. In 2005 the MIPAS measurement scheme underwent a fundamental change from a high- 
resolution mode to a reduced spectral-resolution mode. For time series comparisons we will not make use of the highresolution mode retrievals, but these are included in the bias comparisons when coincidences are available. From 2005 onwards, in addition to a nominal mode, there were a number of special measurement modes. A daily list of the measurement mode for MIPAS is provided at http://eodg.atm.ox. ac.uk/MIPAS/L1B/. Here we will make use of two types of measurement modes: nominal (NOM), in which the lowestaltitude measurements are taken in the troposphere, and middle atmosphere (MA), in which the lowest-altitude measurements are in the lower stratosphere but extend into the thermosphere. MIPAS measurements are processed by four different processing centers: (1) the University of Bologna (Dinelli et al., 2010), (2) the European Space Agency (ESA; Raspollini et al., 2013), IMK/IAA (von Clarmann et al., 2009; Stiller et al., 2012; Garcia-Comas et al., 2016), and Oxford (Payne et al., 2007). All of these retrievals are available for public use. Since certain datasets may be best suited to specific science applications, we include a number of these datasets in this comparison. The four processors differ in several respects, such as their choices of spectral ranges (so called micro-windows), the vertical grid on which the retrievals are performed (pressure or geometric altitude), the choice of regularization (and related to this, the vertical resolution), the choice of spectroscopic database, the sophistication of the radiative transfer (in particular, whether or not non-LTE emissions are considered), and whether or not any attempt is made to account for horizontal inhomogeneities. Some of the different processing schemes also make use of different level-1b data versions (here V5 and V7) based on different ESA calibrations. The spread of results seen for MIPAS indicates how specific choices within a retrieval approach may influence the retrieval results.

The list of retrieval datasets to be included and the color coding that we will use throughout this study are given in Fig. 1. Further details relevant to all of the satellite datasets are given in Walker et al. (in preparation).

\section{Average profile comparisons}

Retrieved profiles from GBMW measurements generally have a vertical resolution of $\sim 10-15 \mathrm{~km}$. Because this is significantly coarser than the typical vertical resolution of the limb scanning satellite measurements used here, the satellite retrievals should generally be convolved before being compared with ground-based retrievals. Thus, instead of comparing the retrieved ground-based profile with the vertical profile $x_{\text {sat }}$, one calculates a convolved satellite profile ( $\left.x_{\text {sat_conv }}\right)$ by applying the equation $x_{\text {sat_conv }}=x_{\mathrm{a}}+\mathbf{A}\left(x_{\mathrm{sat}}-x_{\mathrm{a}}\right)$, where $x_{\mathrm{a}}$ is the a priori mixing ratio profile and $\mathbf{A}$ is the averaging kernel calculated from the microwave measurement. The application of this equation not only helps to address the problem of differences in vertical resolution, but also ensures that, at

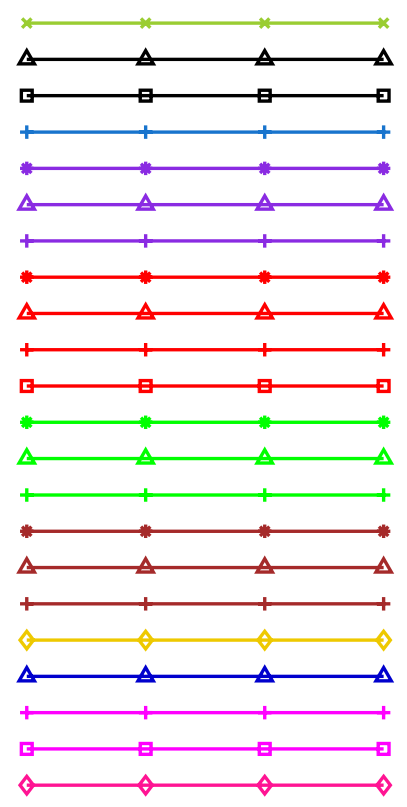

\author{
GBMW \\ ACE-FTS v2.2 \\ ACE-FTS v3.5 \\ HALOE \\ MIPAS-Bologna V5H \\ MIPAS-Bologna V5R NOM \\ MIPAS-Bologna V5R MA \\ MIPAS-ESA V5H \\ MIPAS-ESA V5R NOM \\ MIPAS-ESA V5R MA \\ MIPAS-ESA V7R NOM \\ MIPAS-IMKIAA V5H \\ MIPAS-IMKIAA V5R NOM \\ MIPAS-IMKIAA V5R MA \\ MIPAS-Oxford V5H \\ MIPAS-Oxford V5R NOM \\ MIPAS-Oxford V5R MA \\ MLS \\ SCIAMACHY solar OEM \\ SMR $489 \mathrm{GHz}$ \\ SMR $557 \mathrm{GHz}$ \\ SOFIE
}

Figure 1. The color and symbol scheme used for instruments and their retrieval versions used in comparisons throughout this study.

altitudes where the microwave measurement is insensitive, both the retrieved microwave profile and the convolved satellite profile are equal to the a priori.

A typical set of averaging kernels for the GBMW retrievals used in this study is shown in Fig. 2. Ideally the sum of the kernels for a particular level is $\sim 1.0$, with lower values indicating increased a priori dependence. As is apparent in the figure, the measurement sensitivity of the GBMW retrievals decreases and the vertical resolution degrades with increasing altitude in the upper mesosphere, and the retrieval becomes increasingly dependent upon the a priori mixing ratio profile.

While GBMW retrievals are generally provided over a fixed pressure (or altitude) range, a useful bias comparison should minimize the effect of a priori information in the retrievals. The GBMW profiles used for bias comparisons are therefore all required to have averaging kernels for which the sum of the kernels is at least 0.5 for pressures from 0.03 to $3 \mathrm{hPa}$. We note that the sum of the kernels is a slightly different (but more tractable) measure of sensitivity than measurement response. Tropospheric opacity due to weather conditions can affect the temporal resolution required to achieve a desired sensitivity, and in particularly humid conditions useful GBMW measurements may not be possible. Summer months tend to have a wetter troposphere, degrading the microwave profile measurements; hence there is a tendency for more comparisons to take place during winter months. This is particularly the case for the satellite comparisons with GBMW measurements at ALOMAR and Seoul. 


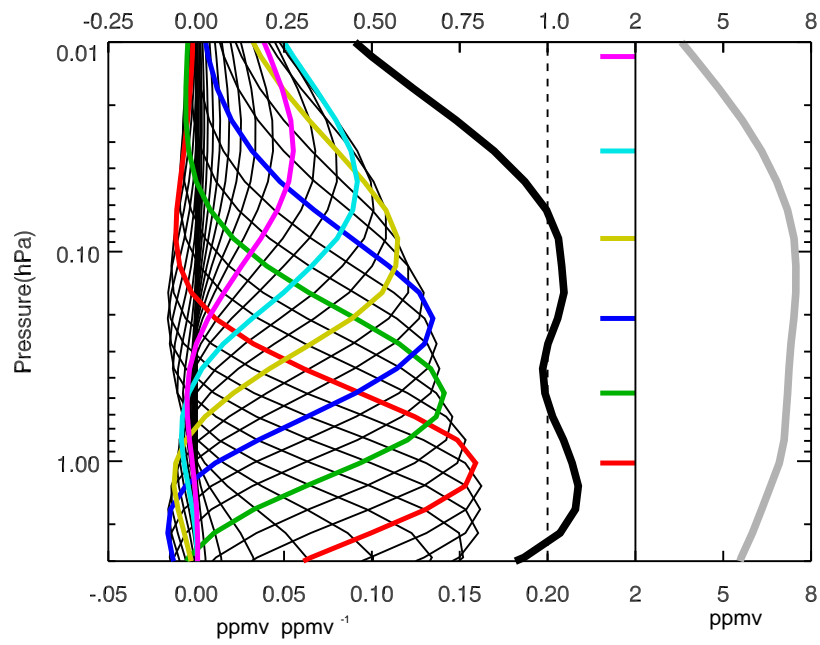

Figure 2. Left: a typical set of averaging kernels for GBMW retrievals (in this case for retrievals from Mauna Loa). The thin lines are referenced to the lower $x$ axis and represent the sensitivity of the measurement to perturbations at individual pressure levels. Certain levels are indicated by colored lines. For these lines the level of the perturbation is indicated by the short colored lines on the right. Generally this colored line is near the peak of the respective kernel, but at the higher altitudes where the sensitivity begins to drop $<1$ an offset develops. The single thick black line is referenced to the upper $x$ axis and indicates the sum of the averaging kernels at that level. Ideally the sum of these kernels is near unity, as indicated by the dashed line. Right: the gray line shows the water vapor profile obtained for this particular retrieval from Mauna Loa.

The equation for the convolution of satellite measurements may require profile information that is outside the altitude range provided by the measuring instrument. This applies here specifically to satellite retrievals that do not extend into the upper mesosphere. To allow for the application of averaging kernels over their full range, the satellite profiles are extended where necessary beyond their standard retrieval range. Above the highest valid satellite retrieval altitude, a climatological profile is used that is scaled to the topmost valid satellite measurement point. In order to minimize the effect of this extension on the comparisons, we include only measurements at altitudes at least $10 \mathrm{~km}$ below the topmost measurement altitude for that particular profile. We then calculate the value $<\mathrm{vmr}_{\text {sat }}-\operatorname{vmr}_{\mathrm{GBMW}}>/<\mathrm{vmr}_{\mathrm{GBMW}}>$ at each altitude based on all of the profiles that reach a particular altitude (once the top $10 \mathrm{~km}$ has been removed). This necessarily results in a different number of comparisons at each level. We then show comparisons only at levels for which, using the criterion above, at least $50 \%$ of the satellite measurements are available; hence the highest comparison altitudes will be $10 \mathrm{~km}$ below the altitude at which $50 \%$ of the satellite measurements are valid.

In Figs. 3 and 4 we show for a number of satellite retrievals the average difference relative to all available ground-based microwave measurements. These differences are calculated from all coincidences for which there is a satellite measurement that is spatially within $1000 \mathrm{~km}$, within $\pm 5^{\circ}$ latitude of the ground-based site, and made either within the integration time range of the GBMW instrument or within $\pm 24 \mathrm{~h}$ of the center of this integration period (for integrations shorter than $48 \mathrm{~h}$ ). All of the satellite measurements shown in Figs. 3 and 4 have been convolved with averaging kernels from the appropriate GBMW instrument.

As can be seen in these figures, the GBMW retrievals are generally slightly lower than those from most satellites over most of the vertical range shown. In comparisons with Aura MLS, this difference is almost everywhere within $10 \%$, indicating good agreement in the shape of the vertical profile. This difference exceeds $10 \%$ only at the highest altitudes at which the mixing ratios decrease rapidly with increasing altitude. This is especially true for the ALOMAR comparison, which takes place preferentially in the winter when mesospheric water vapor is especially low. Only the measurements from ALOMAR show a difference with respect to MLS that goes outside the $0-10 \%$ range at pressures below $0.05 \mathrm{hPa}$. The GBMW comparisons with ACE-FTS are very similar to those with MLS, except that the ACE retrievals are 0$5 \%$ lower. The GBMW instruments operated over different time periods; hence in some cases there is only a short period of coincidences available (most notably at Table Mountain). We have not included in Figs. 3 and 4 any comparisons for which there were fewer than 10 coincidences. Comparisons with HALOE are only available for the three GBMWs that were operational in 2005 (Lauder, Mauna Loa, and Onsala). These GBMW retrievals show higher mixing ratios (up to $\sim 10 \%$ ) than HALOE except near the top altitudes of the comparisons. Thus, the GBMW-retrieved $\mathrm{H}_{2} \mathrm{O}$ mixing ratios are, almost everywhere, larger than those from HALOE, but smaller than those from MLS.

With the exception of the MIPAS version 7 (V7) results, all of the MIPAS retrievals shown in Fig. 4 are from the version 5 (V5) level-1b spectra. As mentioned in Sect. 2.2, the high-resolution (V5H) MIPAS measurements were only available until 2004. The IMK/IAA high-resolution retrievals show mixing ratios that are larger than the GBMW values everywhere, with a maximum difference relative to the three GBMW sites of $\sim 10-20 \%$ near $\sim 1 \mathrm{hPa}$ and minimum differences of $\sim 5 \%$ at $\sim 0.3 \mathrm{hPa}$ (the top of the retrieval range for this satellite measurement). The Bologna high-resolution retrievals are quite similar to the IMK/IAA retrievals, but $\sim 2 \%$ lower. The ESA high-resolution retrievals are generally similar to the IMK/IAA retrievals from 3 to $1 \mathrm{hPa}$, but then drop slightly more rapidly with decreasing pressure. They are available to a slightly lower pressure level than the IMK/IAA retrievals, and at this lowest pressure level $(\sim 0.3 \mathrm{hPa})$ they show mixing ratios $\sim 10-15 \%$ lower than those retrieved from the GBMW measurements. Conversely, the Oxford high-resolution retrievals, which show mixing ratios similar to the other two high-resolution retrieval versions 

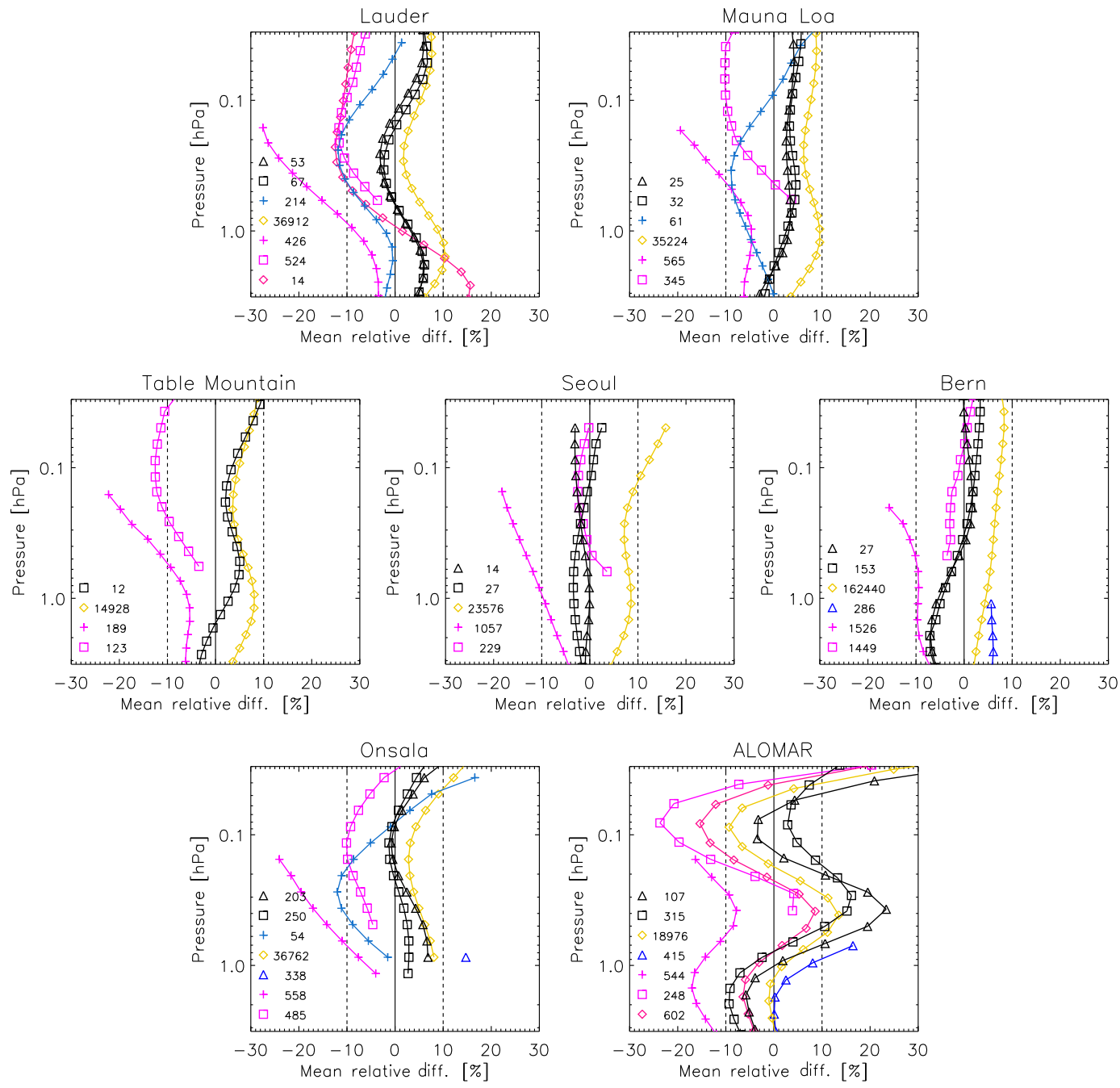

Figure 3. The average difference between coincident non-MIPAS satellite measurements and ground-based measurements at seven sites shown from south to north. Results are shown from 3 to $0.3 \mathrm{hPa}$. The difference shown is convolved satellite minus GBMW using the satellite symbols given in Fig. 1. The numbers on the left of each panel indicate the number of coincidences.

up to $\sim 0.5 \mathrm{hPa}$, show higher mixing ratios at the top few levels and are $10-15 \%$ higher than the GBMW at $\sim 0.3 \mathrm{hPa}$.

The NOM MIPAS retrievals taken in the reduced spectralresolution measurement mode since 2005 are generally available up to $\sim 0.2 \mathrm{hPa}$. With the exception of the comparisons near ALOMAR, they all show mixing ratios higher than those from the GBMW retrievals at pressure levels from 3 to $\sim 0.6 \mathrm{hPa}$. The largest difference in this pressure range is at Lauder, where the MIPAS NOM retrievals are all up to $\sim 20 \%$ larger near $\sim 2 \mathrm{hPa}$. The ESA retrievals tend to give the highest mixing ratios among the MIPAS NOM V5R retrievals, but this is not the case for the ESA NOM V7R retrievals. Between $\sim 0.6$ and $\sim 0.2 \mathrm{hPa}$ the GBMW and MIPAS NOM retrievals always agree to within $\sim 10 \%$. At altitudes just above $3 \mathrm{hPa}$, the MIPAS comparisons show an increase in water vapor with increasing altitude relative to the available GBMW measurements at five of the six sites.
The MA MIPAS retrievals are intended for studies at higher altitudes than the NOM retrievals. The MA retrievals from ESA and Bologna are shown in Fig. 4 to have very similar averages to the NOM version, but the ESA MA retrieval does go to a slightly higher altitude. The IMK/IAA and Oxford MA retrievals cover the entire pressure range shown. The IMK/IAA MA retrievals show decreasing mixing ratios with increasing altitude relative to the GBMW instruments (with the exception of ALOMAR) from approximately the stratopause to $0.1 \mathrm{hPa}$ and tend to be approximately constant at higher altitudes. The Oxford MA retrievals similarly show a decrease relative to the GBMW retrievals with increasing altitude over much of the mesosphere, but this decrease tends to be much more gradual after starting at a higher altitude. As a result, at $\sim 0.2 \mathrm{hPa}$ the Oxford retrievals generally show mixing ratios $\sim 5-10 \%$ larger than those from the GBMW 

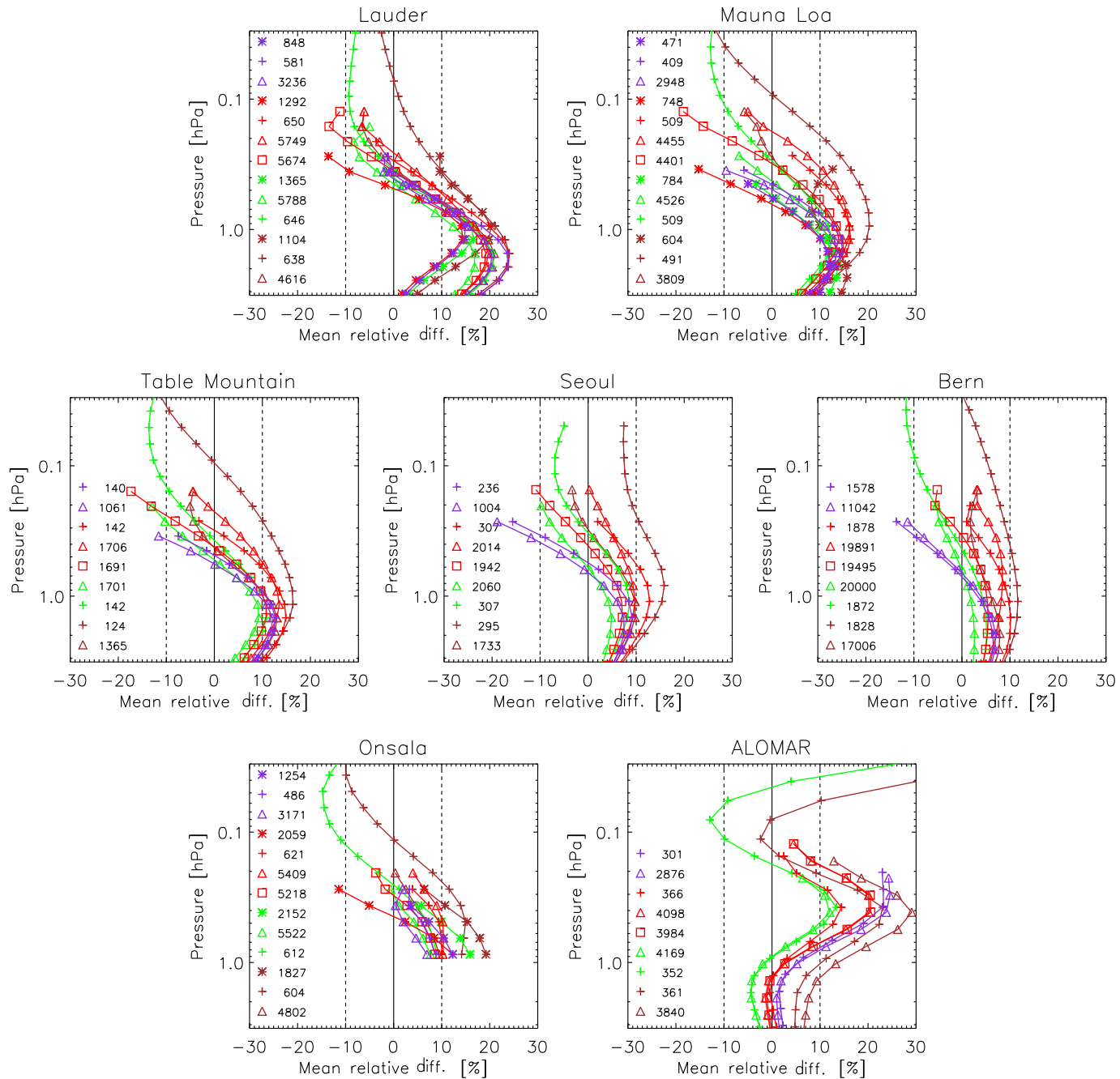

Figure 4. Same as Fig. 3, only for comparisons between various MIPAS retrievals and ground-based measurements.

retrievals, while the IMK/IAA retrievals are generally $\sim 5 \%$ lower than the GBMW retrievals.

Comparisons with the $557 \mathrm{GHz}$ SMR retrieval cover the top of the altitude range shown in Fig. 3 and those with the $489 \mathrm{GHz}$ retrieval cover the bottom. Both SMR retrievals are generally $0-10 \%$ lower than the GBMW retrievals, with the $557 \mathrm{GHz}$ retrieval somewhat larger in the region of overlap. The top of the $489 \mathrm{GHz}$ retrieval $(\sim 0.16 \mathrm{hPa})$ is $20-30 \%$ lower than the GBMW retrieval in all but one of the comparisons. SOFIE comparisons are only possible at the highlatitude $\left(69^{\circ} \mathrm{N}\right)$ ALOMAR site, where they show mixing ratios that are lower at most levels than any instrument except SMR. Similar to the other satellite comparisons at this site, the SOFIE retrievals show a minimum with respect to the GBMW near $\sim 2 \mathrm{hPa}$ and near $\sim 0.07 \mathrm{hPa}$. SCIAMACHY comparisons are only possible with the three northernmost sites, i.e., Bern, Onsala, and ALOMAR, and only at the highest pressure levels (there is only one level of overlap with Onsala). The differences are $\sim 5 \%$ at Bern, $\sim 13 \%$ at Onsala, and vary between $\sim 0$ and $16 \%$ at ALOMAR, where the variation with pressure matches that of most other satellite-based retrievals in this pressure range.

\section{Relative instrumental drifts}

In this section, we will examine temporal variations in the six $\mathrm{H}_{2} \mathrm{O}$ datasets with at least 4 years of data. In order to allow for a detailed study of these variations we will focus on the $0.46 \mathrm{hPa}$ pressure surface. There are both instrumental and geophysical reasons for focusing this study on temporal change in the lower mesosphere.

Retrievals from GBMW instruments can provide information from the mid-stratosphere to the upper mesosphere. However, as mentioned in Sect. 1, the stability of the groundbased $\mathrm{H}_{2} \mathrm{O}$ measurement datasets degrades with decreasing altitude in the stratosphere. In the upper mesosphere the $\mathrm{H}_{2} \mathrm{O}$ emission becomes weaker with increasing altitude; hence the 
retrievals become increasingly dependent upon the a priori (Fig. 2). Retrievals in this region require increasingly long integration periods to achieve a given measurement sensitivity. The best altitude region for ground-based microwave measurements to study long-term changes in $\mathrm{H}_{2} \mathrm{O}$ is therefore the lower mesosphere. Fortunately, the lower mesosphere is geophysically also an ideal region for the study of long-term changes in $\mathrm{H}_{2} \mathrm{O}$.

In the stratosphere $\mathrm{H}_{2} \mathrm{O}$ increases with altitude as $\mathrm{CH}_{4}$ is oxidized (Le Texier et al., 1988; Wrotny et al., 2010). As this oxidation occurs gradually, the amount of $\mathrm{H}_{2} \mathrm{O}$ that has been produced by this process in the stratosphere depends upon the age of the parcel, and this is affected by variations in dynamics. This sensitivity to dynamics-driven changes shows up in the amplitude of the seasonal cycle, and some latitudes (particularly from the tropics to SH midlatitudes) have a large annual cycle in the upper stratosphere (cf. Lossow et al., 2017). Once air has reached the lower mesosphere, however, almost all of the $\mathrm{CH}_{4}$ has been oxidized, and hence these dynamical variations no longer change the amount of $\mathrm{H}_{2} \mathrm{O}$ in an air parcel.

Studies in the upper mesosphere are complicated by an increasingly large seasonal cycle (especially in percentage terms) with increasing altitude, especially at higher latitudes (Lossow et al., 2017; Fig. 1). In addition, in the upper mesosphere variations in Lyman- $\alpha$ radiation cause variations in the photodissociation of $\mathrm{H}_{2} \mathrm{O}$, and this causes both solarcycle-driven decadal-scale changes (Nedoluha et al., 2009) and diurnal changes (Scheiben et al., 2013) in $\mathrm{H}_{2} \mathrm{O}$, both of which increase rapidly with increasing altitude.

In the lower mesosphere, however, interannual variations in $\mathrm{H}_{2} \mathrm{O}$ primarily reflect the changes in $\mathrm{H}_{2} \mathrm{O}$ and $\mathrm{CH}_{4}$ entering the stratosphere. As shown in Fig. 2.2 of IPCC Chapter 2 (Hartmann, et al., 2013), the increase in $\mathrm{CH}_{4}$ has been $\sim 50 \mathrm{ppbv}$ since the mid-1990s, which once fully oxidized would result in a gradual increase in $\mathrm{H}_{2} \mathrm{O}$ of $\sim 0.1 \mathrm{ppmv}$, or $\sim 1-2 \%$, over the past 2 decades. Interannual variations in $\mathrm{H}_{2} \mathrm{O}$ in the lower mesosphere on shorter timescales than this must be attributed to other physical mechanisms, such as variations in $\mathrm{H}_{2} \mathrm{O}$ entering the lower stratosphere, and it has been suggested that the changes observed in $\mathrm{H}_{2} \mathrm{O}$ in the lower mesosphere from 2004-2013 were not inconsistent with the effects of changes in tropical tropopause temperatures (Nedoluha et al., 2013b).

For comparisons in the lower mesosphere we choose coincidence criteria based on the measurements (both satellite and ground-based) and the geophysical properties of this region. Since, unlike for the overall bias comparisons, we require coincident measurements over a number of separate time intervals, we use a coarser set of coincidence criteria than were used in Sect. 3. For most instruments we use a latitudinal coincidence criterion of $\pm 5^{\circ}$ and longitudinal coincidence of $\pm 30^{\circ}$. If we calculate the standard deviation of the differences between any two sets of coincident measurements (using coincidence criteria of \pm 3.5 days and $\pm 5^{\circ}$ latitude) we find that $\sigma$ values are generally within the range 0.3 to $0.7 \mathrm{ppmv}$ (4-10\%). Assuming 52 weeks of coincident measurements in a year, this would result in a formal $2 \sigma$ error of up to $\sim 0.2$ ppmv $(\sim 3 \%)$ for an annual average. The standard deviation of the differences remains very similar whether or not one imposes a longitude coincidence criterion or uses a zonal average.

For the sparser solar occultation measurement datasets (HALOE, ACE, and SCIAMACHY) we do not impose any longitudinal coincidence criteria, but use the zonal average of measurements within $\pm 5^{\circ}$ latitude. We also extend the temporal coincidence to \pm 7 days. Under nominal operation conditions HALOE and ACE typically measure near a midlatitude site $\sim 10-15$ times per year, and hence the formal $2 \sigma$ error for an annual average might be as large as $\sim 0.4$ ppmv $(\sim 6 \%)$.

Aura MLS has been providing nearly global daily coverage of $\mathrm{H}_{2} \mathrm{O}$ in the middle atmosphere since August 2004 and thus provides an ideal dataset to which the other measurements can be compared during this entire period. We first compare these measurements to the six available groundbased measurements and to other available satellite measurements coincident with these ground-based stations in order to evaluate the consistency with which variations in $\mathrm{H}_{2} \mathrm{O}$ are tracked by the different instruments. All of the comparisons are based on annual averages measured at $0.46 \mathrm{hPa}$. Note that while the ground-based sites do cover a range of latitudes, the latitude range is by no means complete and there is only one site in the Southern Hemisphere.

Unlike in Sect. 3, we are not exclusively showing coincidences between satellite and ground-based measurements and therefore have not convolved the satellite data with averaging kernels from the ground-based instruments. At the $0.46 \mathrm{hPa}$ level, neither the water vapor profile nor the anomalies in the profile change rapidly with altitude, and the ground-based retrievals are only weakly dependent upon the a priori mixing ratio profile; hence the difference between convolved and unconvolved results is indistinguishable on most subsequent figures. We will point out where this is not the case.

We have added one additional retrieval dataset here and in Sect. 5. This is the MIPAS-ESA V7R NOM dataset. The MIPAS V7 retrievals differ from the MIPAS V5 retrievals in that they use the level- $1 b$ radiances version 7 for which a timedependent nonlinearity correction scheme has been adopted to account for the change in nonlinearities over the course of the mission due to the aging of the detectors (Valeri et al., 2017). This correction introduces an altitude-dependent temporal change in the MIPAS retrievals. The difference in the temporal variations between the MIPAS-ESA V7R NOM and MIPAS ESA V5R NOM datasets can be taken as representative of temporal variations between any of the MIPAS $\mathrm{V} 7$ and V5 retrievals at $0.46 \mathrm{hPa}$.

In Fig. 5 we show the percentage difference between the annual average for coincident measurements (both 

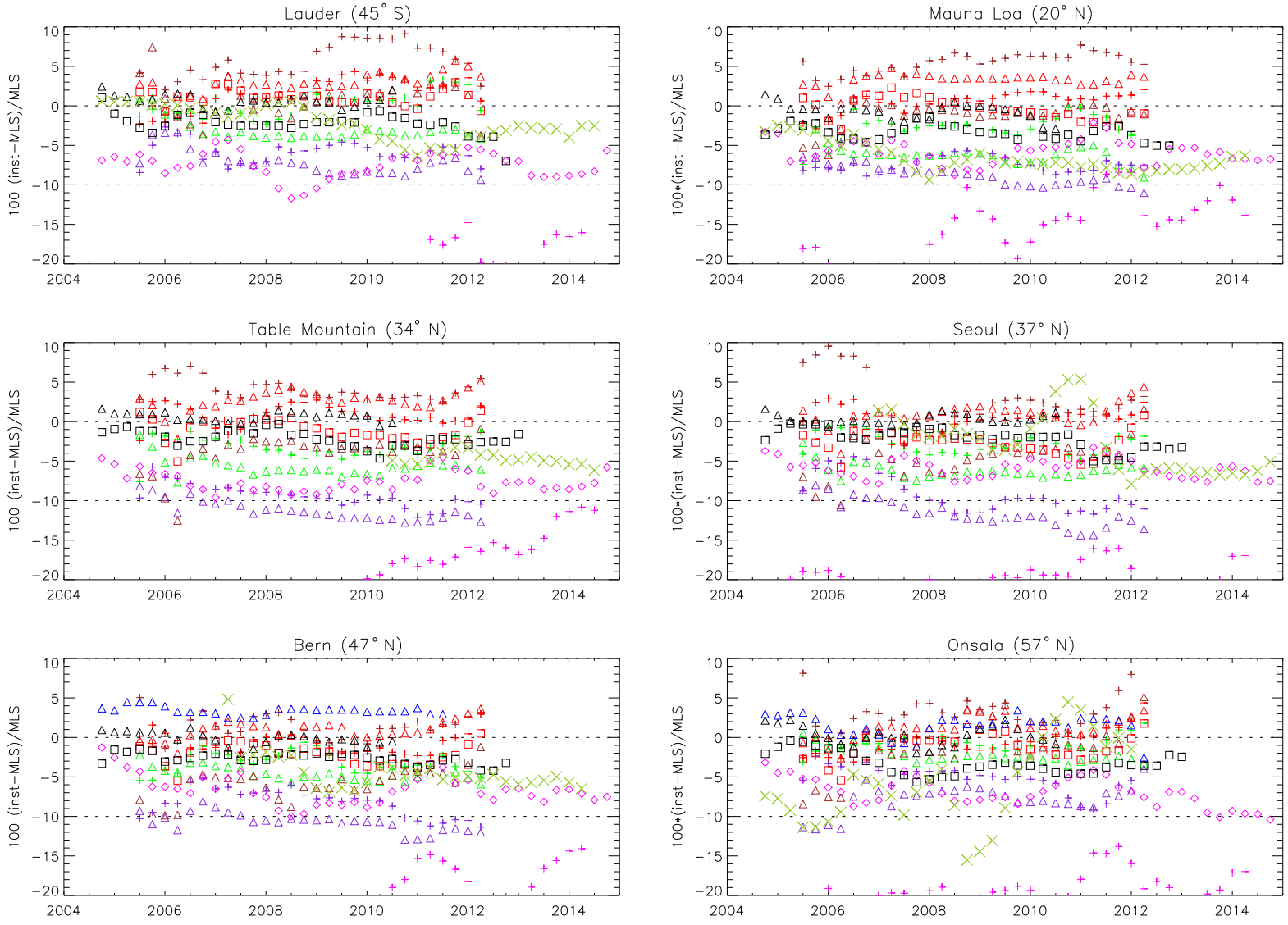

Figure 5. Annual average differences between coincident $\mathrm{H}_{2} \mathrm{O}$ measurements at $0.46 \mathrm{hPa}$. Results are shown at six ground-based sites and all differences are with respect to MLS measurements at those sites. Annual average differences are shown four times per year (see text). The symbols used are from Fig. 1 and indicate the instrument that is being compared with MLS.

satellite and ground-based) with MLS, i.e., $f_{\text {inst }}(t)=$ $100\left(\mathrm{vmr}_{\text {inst }}-\mathrm{vmr}_{\mathrm{MLS}}\right) / \mathrm{vmr}_{\mathrm{MLS}}$ averaged over all measurements for a full year. The colors and symbols, which are those shown in Fig. 1, are based upon the instrument being compared with MLS. These annual averages are shown four times per year, covering approximately January-December, April-March, July-June, and October-September, with symbols plotted in the middle of the averaging period. Each measurement is therefore included in four of the anomaly data points shown in the figure. The $489 \mathrm{GHz}$ SMR data are lower than most of the other measurements and show a strong positive trend; hence, while there are data throughout this time period, many of the measurements towards the beginning of the time period do not appear in Fig. 5.

Figure 5 shows that at $0.46 \mathrm{hPa}$ the annual average mixing ratios measured by GBMW instruments are, with a few temporary exceptions between $\sim 0$ to $10 \%$ lower than MLS (as in Figs. 3 and 4). An interesting point to note is that of the six GBMW instruments, five have a lower mixing ratio relative to MLS at the end of the time series than at the beginning (although in the case of Table Mountain this difference is only $\sim 1 \%$ ). While there is a drop in the GBMW measurements relative to MLS, the precise timing of this downward drift relative to MLS is not the same for all of these instruments. The drop in GBMW mixing ratio relative to MLS at Mauna Loa occurs primarily from 2005 to 2008, the drop at Bern occurs from 2007 to 2009, and the drop at Lauder occurs from 2008 to 2011. Although most of the GBMW measurements do show an overall negative trend relative to MLS, perhaps the most important conclusion that can be drawn from these comparisons is that there is no particular period during which a preponderance of measurements shows a clear increase or decrease relative to MLS.

The sign of the drift between the GBMW and MLS measurements is consistent with that reported by Hurst et al. (2016), who found that frost point hygrometer measurements at four of five sites showed a drift relative to MLS of -0.6 to $-1.5 \% \mathrm{yr}^{-1}$. However, the results shown in Hurst et al. (2016) indicate that this drift began around 2010. From 2010 to 2014 the Lauder, Mauna Loa, Table Mountain, and Bern instruments are all stable relative to MLS. The GBMW instrument at Seoul does show a very large drop relative to MLS from 2010 to 2012, while for the GBMW instrument at Onsala we only have data to the end of 2012 pending a repro- 

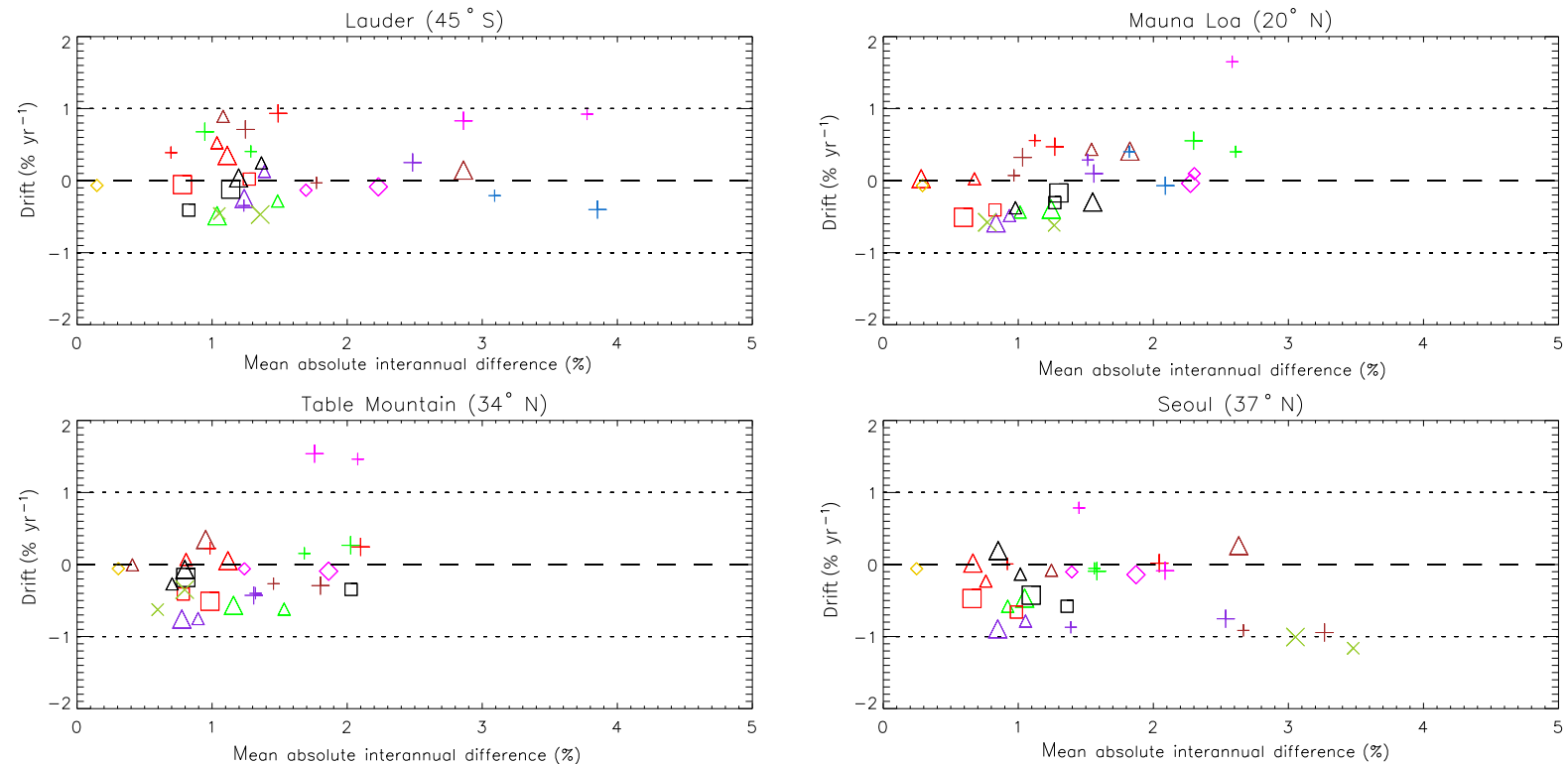

Bern $\left(47^{\circ} \mathrm{N}\right)$
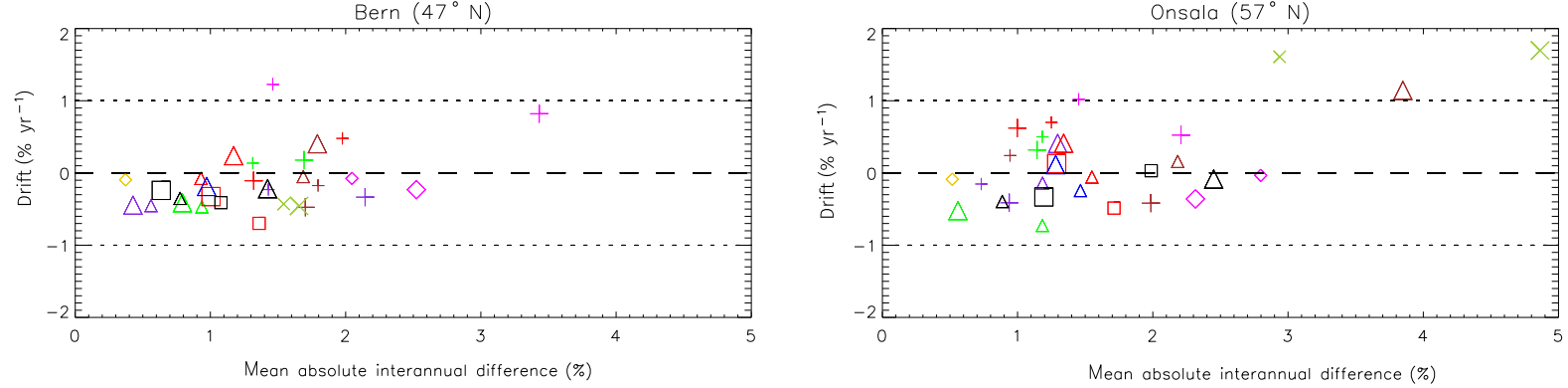

Figure 6. The drift ( $y$ axis) and mean absolute interannual difference ( $x$ axis) between coincident $\mathrm{H}_{2} \mathrm{O}$ measurements at $0.46 \mathrm{hPa}$. Results are shown at six ground-based sites and, unless otherwise indicated, all differences are with respect to MLS measurements at those sites. The large symbols indicate differences for coincident comparisons, as were shown in Fig. 2. The small symbols indicate comparisons of annual average differences from climatologies (see text for details). The symbols used are from Fig. 1 and indicate the instrument that is being compared with MLS. The MLS symbol shows the results of comparisons between convolved and unconvolved MLS measurements. The overlap period between HALOE and MLS is too short for these analyses, but we do perform these analyses for GBMW vs. HALOE comparisons at Lauder and Mauna Loa. These are indicated using the HALOE symbols from Fig. 1.

cessing of the dataset. Just as for the GBMW-MLS intercomparisons, most of the satellite retrievals are also lower than but within $10 \%$ of MLS during most of the comparison period. Exceptions are the SCIAMACHY, MIPAS Oxford MA, and MIPAS ESA NOM retrievals, which are almost always higher than MLS, as well as the $489 \mathrm{GHz}$ SMR retrievals, which are almost always more than $10 \%$ lower.

Figure 6 provides some statistical measures of the relative stability of the measurement datasets shown in Fig. 5. In calculating the results for Fig. 5 we use the calendar year average differences from Fig. 5 and simply fit a two-term linear trend so that $f_{\text {inst }}(t)=A_{0}+A_{1} t$. The drift, as measured by the linear trend $\left(A_{1}\right)$ term, thus provides an estimate of the relative stability of trends for each dataset relative to MLS over the entire period of the instrument comparison. The $x$ axis in Fig. 6 shows the variation in the mean absolute interannual difference from the calendar year averages, i.e., $x_{\text {inst }}=<\left|f_{\text {inst }}(t)-<f_{\text {inst }}(t)>\right|>$. This gives an indication of the accuracy to which it is possible to measure year-to-year variability.

In addition to showing these statistics specifically for the temporally coincident measurements, we have also included in Fig. 6 smaller symbols that show annual average differences between MLS and a comparison instrument for all measurements taken near a site over the same time years. The annual averages are calculated as follows. First, we calculate an instrument-specific climatology $C_{\text {inst }}(t)$ for all measurements coincident with each site by fitting each dataset with a five-parameter fit:

$$
\begin{aligned}
& C_{\text {inst }}(t)=A_{1}+A_{2} \sin (2 \pi t)+A_{3} \cos (2 \pi t)+A_{4} \sin (4 \pi t) \\
& \quad+A_{5} \cos (4 \pi t),
\end{aligned}
$$

where $t$ is in years. We then subtract $C_{\text {instrument }}(t)$ from the measurements for that year and calculate an average annual 
anomaly. The subtraction of the seasonal fit from the data should reduce the effects of year-to-year seasonal variations in the sampling.

We include both types of comparisons because we would like to assess the uncertainty in the annual average $\mathrm{H}_{2} \mathrm{O}$ variations. In cases for which both the MLS and the comparison measurement are available nearly continuously, the two methods should give nearly the same result, and this is the case. However, if one uses this method for temporally limited samples, such as for SCIAMACHY measurements near Bern (a latitude that SCIAMACHY reaches only from mid-May to mid-July), then the best fit to Eq. (1) can result in unphysical annual cycles, so the relative drift analysis is best done with coincident comparisons. SCIAMACHY measurements are also made near Onsala, and while there is an offset between the two methods, the variations calculated by the two methods are similar. In general, comparisons of annual data are most difficult at higher latitudes because of the larger annual cycles and because sudden warmings can result in rapid descent, which causes rapid changes in the $\mathrm{H}_{2} \mathrm{O}$ mixing ratio at a particular altitude (cf. Straub et al., 2012). In cases such as this, annual averages can be significantly affected by whether or not measurements are taken during a particular period.

In addition to the comparisons with MLS we also include in Fig. 6, using the HALOE colors from Fig. 1, comparisons between HALOE and the GBMW at Mauna Loa and Lauder. The mean interannual differences between the HALOE-GBMW pairs (shown in HALOE colors) are clearly much larger than between the MLS-GBMW pairs (shown in GBMW colors) at these sites. To some extent this may be because calculated HALOE trends are necessarily based on sparser sampling than MLS, but we also note that significant steps have been taken to improve the stability of the GBMW instruments at these two sites since the 1990s (Gomez et al., 2012), so the better MLS-GBMW agreement is probably, at least to some extent, a result of improved GBMW stability for the Lauder and Mauna Loa systems.

Also included in Fig. 6 is a comparison of drift and interannual differences between MLS measurements at $0.46 \mathrm{hPa}$ and MLS measurements for this level after convolution with the GBMW averaging kernels. The drift between the MLS and convolved MLS variations is $<0.1 \%$, and the mean absolute interannual difference is largest at Onsala, where it is $<0.6 \%$.

Figure 6 shows that from one year to the next, the difference between the annual average $\mathrm{H}_{2} \mathrm{O}$ measured by MLS and by one of the other instruments included in this study, using either comparison method, is $\sim 1 \%$; $\sim 34 \%$ of the comparisons above show a mean absolute interannual difference of $<1 \%$, and $\sim 48 \%$ show a difference of $<1.2 \%$. Based on the MLS data, the interannual variation in the geophysical mean for these six sites over the period during which MLS has been making measurements is $\sim 1.4 \%$.
With the exception of the GBMW instrument at Onsala, all of the GBMW instruments show a negative drift relative to MLS. Four of the instruments (Lauder, Mauna Loa, Bern, and Table Mountain) show drifts that are $\sim-0.5 \% \mathrm{yr}^{-1}$. At Mauna Loa, Bern, and Table Mountain the drifts relative to MLS of the GBMW instruments are quite similar to those of the MIPAS-ESA V7 NOM retrieval, whereas at the Southern Hemisphere Lauder site almost all of the MIPAS retrievals show a more positive drift.

We cannot definitively conclude from the drift and average profile analysis that there is a clearly preferred dataset for MIPAS. The MIPAS MA retrievals are designed for studies at higher altitudes than the NOM retrievals, and Fig. 4 provides the useful ranges for the MIPAS MA and NOM retrievals in the upper stratosphere and mesosphere. Some studies in the upper mesosphere must necessarily make use of the MA retrievals, and in some cases only specific MA retrievals may be sufficiently sensitive at the levels required. The results for the mean absolute interannual differences in the lower mesosphere shown in Fig. 6 indicate that neither the MA nor the NOM retrievals are consistently more similar to MLS retrievals, but there are some MIPAS retrievals that, at some sites and during some periods, show larger-than-usual variations when compared to other instruments. We therefore hope that the results shown in Figs. 5 and 6 will help to guide those interested in using MIPAS for science studies for multiyear analyses. While the MIPAS V7 retrievals do account for a known change in the instrument and thus should in principle be preferred over other retrieval versions, the difference between the V7R NOM and V5R NOM retrievals is not sufficiently large for us to conclude, based on comparisons with other instruments, that either is superior.

\section{Measured changes in water vapor}

From the similarity of the large and small symbols in Fig. 6, we conclude that comparisons of coincident measurements generally produce drifts and interannual differences that are similar to those calculated from anomalies relative to instrument-specific climatologies. Thus, the anomalies relative to instrument-specific climatologies give useful estimates of interannual variations. Having reached this conclusion, we shall proceed to show interannual variations relative to such instrument-specific climatologies.

In Fig. 7 we show these annual anomalies plus the constant term $\left(A_{1}\right)$ from the five-parameter fit. We start the time series in 1996, since this is the first year for which at least two of the ground-based measurement datasets are available. Figure 7 allows us to investigate not just variations relative to MLS, but also geophysical variations as observed by each instrument.

The only instruments measuring during much of the 19962004 period are HALOE and the GBMW instruments at Mauna Loa and Lauder. The GBMW measurements from 

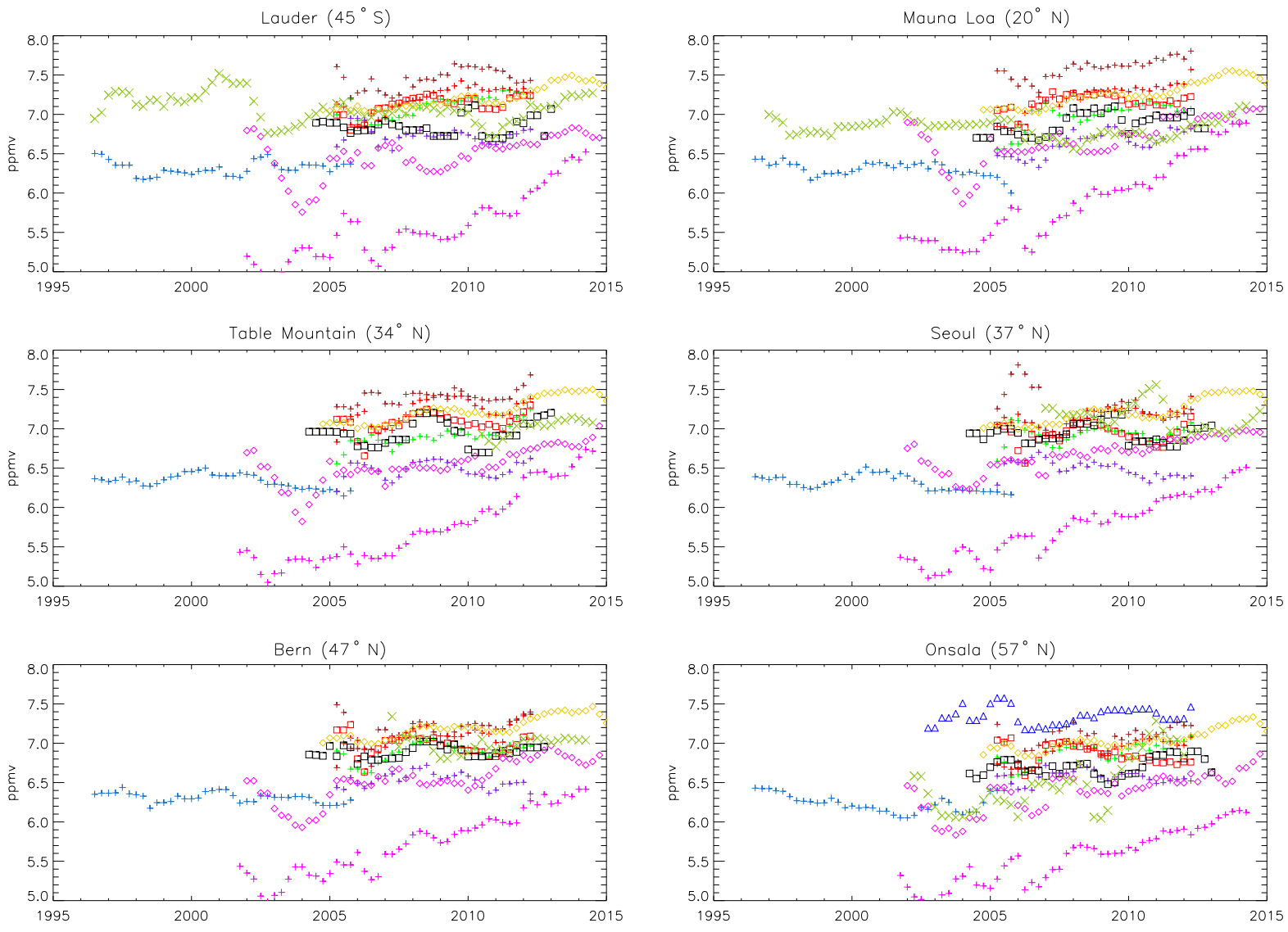

Figure 7. Measurements since 1996 at $0.46 \mathrm{hPa}$ from or coincident with six NDACC sites. The results shown are the annual anomaly plus the constant term from the five-parameter fit (see text). Values are shown four times per year. Symbols and colors are from Fig. 1.

Lauder from 1996-2004 show more interannual variability than HALOE, but the overall change from the beginning to the end of this time period is small. The difference between measurements taken during the calendar years 1996 and 2004 is +0.08 ppmv for the GBMW and -0.17 ppmv for HALOE. The GBMW measurements from Mauna Loa show much less interannual variation and also only a small overall change from 1996-2004. The difference between the annual average from the GBMW measurements from July 1996 to June 1997 (i.e., the first full year of measurements) and those for the 2004 calendar year is $-0.11 \mathrm{ppmv}$, while for the HALOE measurements over this period the difference is $-0.17 \mathrm{ppmv}$. Measurements from the GBMW at Onsala become available in 2002. In agreement with the $557 \mathrm{GHz}$ SMR measurements, these show a large decrease from 2002 to 2003 ( $-0.6 \mathrm{ppmv}$ in the GBMW and $-0.5 \mathrm{ppmv}$ in the SMR measurements), but this change is not observed in the HALOE and SCIAMACHY datasets and only to a smaller extent in the $489 \mathrm{GHz}$ SMR dataset.

There was a decrease in water vapor measured by many instruments at $0.46 \mathrm{hPa}$ between 2005 and 2006. The calendar year 2006 MLS measurement anomalies at all six sites were lower than those in 2005 by $-0.05 \mathrm{ppmv}$ at Lauder and -0.17 ppmv at Onsala; 76 of the $89(85 \%)$ retrieval sets showed a decrease in the annual anomalies between 2005 and 2006. From 2006 onwards there has been an increase in $\mathrm{H}_{2} \mathrm{O}$ at these altitudes, as was shown by Nedoluha et al. (2013b). They noted very good agreement between the increase observed by GBMW measurements from Mauna Loa and global measurements from MLS and MIPAS when comparing annual averages for 2006 and 2011.

While there seems to have been a general decrease in $0.46 \mathrm{hPa}$ water vapor between 2005 and 2006, the opposite occurred between 2007 and 2008. If we compare the calendar year 2008 and 2007 measurement anomalies from MLS we find that there was an increase at all sites except Lauder (i.e., all of the Northern Hemisphere sites). The increases ranged from +0.05 ppmv at Mauna Loa to +0.16 ppmv at Bern; 71 of the $76(93 \%)$ retrieval datasets showed an increase in annual anomalies between 2007 and 2008.

One apparent feature in Fig. 7 is that the annual average $\mathrm{H}_{2} \mathrm{O}$ mixing ratio for almost all of the retrievals is almost always larger than that measured by HALOE at any time. This helps to emphasize that the interannual or even decadal-scale 


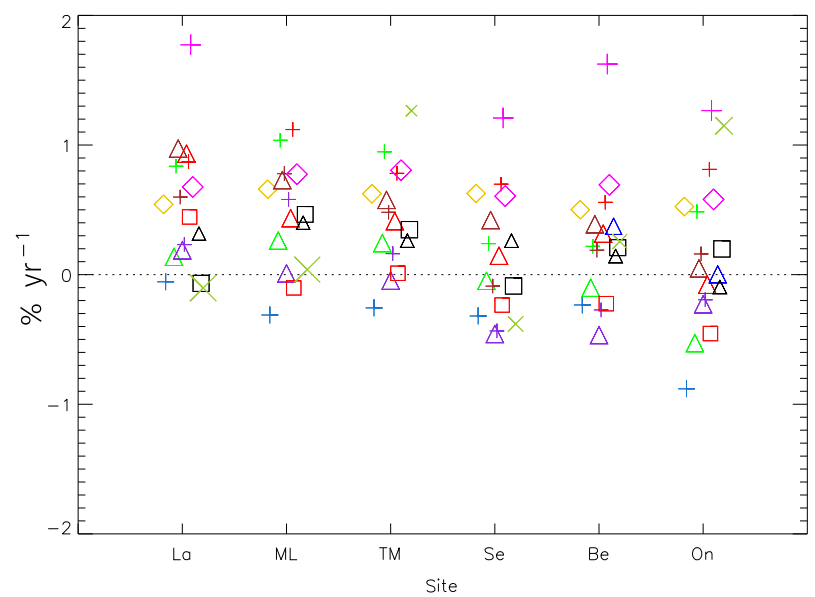

Figure 8. Linear trends at $0.46 \mathrm{hPa}$ at each of the six NDACC ground-based sites. Trends are calculated over the data collection period for each instrument shown in Fig. 6. The sites are listed from south to north: Lauder $\left(45^{\circ} \mathrm{S}\right)$, Mauna Loa $\left(20^{\circ} \mathrm{N}\right)$, Table Mountain $\left(34^{\circ} \mathrm{N}\right)$, Seoul $\left(37^{\circ} \mathrm{N}\right)$, Bern $\left(47^{\circ} \mathrm{N}\right)$, and Onsala $\left(57^{\circ} \mathrm{N}\right)$. Symbols are slightly offset from each other along the $x$ axis for legibility. Larger symbols indicate longer datasets.

variations in $\mathrm{H}_{2} \mathrm{O}$ are generally smaller than the absolute differences between instruments. Any understanding of longterm changes in $\mathrm{H}_{2} \mathrm{O}$ would therefore be irreparably harmed by measurement gaps. Such gaps would eliminate the critical period of comparison of coincident measurements to understand absolute differences.

In Fig. 8 we show linear trends derived from each full dataset, and thus the calculated trends cover many different time periods, although the period between 2004 and 2012 is especially well represented. Since trends, especially those calculated from the shorter time series, may be affected by the phase of the QBO during which measurements start or end, we use in this case an eight-parameter fit:

$$
\begin{aligned}
& C_{\text {inst }}(t)=A_{1}+A_{2} \sin (2 \pi t)+A_{3} \cos (2 \pi t)+A_{4} \sin (4 \pi t) \\
& \quad+A_{5} \cos (4 \pi t)+A_{6} \mathrm{QBO} 30(t) \\
& \quad+A_{7} \mathrm{QBO} 50(t)+A_{8} t,
\end{aligned}
$$

where QBO30 and QBO50 are the 30 and $50 \mathrm{hPa}$ zonal wind anomalies from the Climate Prediction Center (www.cpc. ncep.noaa.gov/data/indices).

Figure 8 shows that most retrievals indicate an increase in $\mathrm{H}_{2} \mathrm{O}$, with the MLS measurements showing an increase of $\sim 0.5 \% \mathrm{yr}^{-1}$ at all sites. The MIPAS measurements cover a similar but slightly shorter period than MLS, and while most of these retrievals show positive trends, the single MIPAS V7 retrieval shown here shows a negative trend at the Northern Hemisphere sites. The HALOE measurements, because we have limited this study to measurements from the beginning of 1996 onwards, show a negative trend. However, we note that if we include the full HALOE dataset back to 1991, then the overall trend is between +0.1 and $+0.6 \% \mathrm{yr}^{-1}$ at all sites. The two longest datasets, the GBMW measurements from Lauder and Mauna Loa, show very little change since 1996. The difference between the first and last annual averages shown in Fig. 7 for these two instruments is +0.27 ppmv at Lauder and +0.13 ppmv at Mauna Loa. This compares to an expected increase in $\mathrm{H}_{2} \mathrm{O}$ from $\mathrm{CH}_{4}$ oxidation over this time period of $\sim+0.1 \mathrm{ppmv}$ and hence implies that there has been very little increase in $\mathrm{H}_{2} \mathrm{O}$ entering the stratosphere since 1996. However, the Lauder and Mauna Loa GBMW instruments show a negative trend of $\sim-0.5 \% \mathrm{yr}^{-1}$ relative to the MLS measurements. If this relative change indicates a problem with the GBMW measurements over the past decade then this would add $\sim+0.35$ ppmv to the change in $\mathrm{H}_{2} \mathrm{O}$ mixing ratio, an increase that would clearly imply an increase in $\mathrm{H}_{2} \mathrm{O}$ entering the stratosphere.

\section{Summary}

We compared satellite and GBMW measurements at a number of sites. We began with profile comparisons at seven sites from 3 to $0.03 \mathrm{hPa}$. Comparisons between satellite and GBMW measurements over this range of pressures generally showed agreement within $10 \%$, with most satellite retrievals showing altitude varying differences resulting in lower mixing ratios than the GBMW retrievals at some levels and higher mixing ratios at others. The exception to this rule was the GBMW-MLS comparisons, which had vertical profiles with very similar shapes. As a result, at six of the seven sites, these comparisons showed that the MLS-measured water vapor was between 0 and $10 \%$ higher at almost all levels than the GBMW-measured water vapor.

Temporal variations on annual scales were studied at six NDACC sites. This analysis was limited to the $0.46 \mathrm{hPa}$ level, a level which is ideal for the study of $\mathrm{H}_{2} \mathrm{O}$ trends for both geophysical and instrumental reasons. We compared the interannual variation in all of the available measurements with MLS at the six sites using two different intercomparison methods and found that the relative variation between MLS and other measurement datasets in the annual average was typically $\sim 1 \%$. We did find that four of the GBMW instruments showed trends relative to MLS of $\sim-0.5 \% \mathrm{yr}^{-1}$, but we noted that there were differences in the detailed temporal evolution of that drift. At Mauna Loa, Bern, and Table Mountain the drifts of the GBMW instruments relative to MLS are quite similar to those of the MIPAS-ESA V7 NOM retrieval, whereas at the Southern Hemisphere Lauder site almost all of the MIPAS retrievals show a more positive drift. We also found that at all sites MLS showed an increase of $\sim 0.6 \% \mathrm{yr}^{-1}$.

We also compared trends in $\mathrm{H}_{2} \mathrm{O}$ at all of the sites over the measurement time period that was available for each instrument. The longest retrieval datasets showed $\mathrm{H}_{2} \mathrm{O}$ trends at $0.46 \mathrm{hPa}$ of $+0.1 \% \mathrm{yr}^{-1}$ (GBMW at Mauna Loa) and 
$-0.1 \% \mathrm{yr}^{-1}$ (GBMW at Lauder) from 1996-2015. The preponderance of retrievals was concentrated over the 20042012 period, and most of these showed trends of between 0 and $+1 \% \mathrm{yr}^{-1}$.

Data availability. All data used here are publicly available upon request.

Competing interests. The authors declare that they have no conflict of interest.

Special issue statement. This article is part of the special issue "Water vapour in the upper troposphere and middle atmosphere: a WCRP/SPARC satellite data quality assessment including biases, variability, and drifts (ACP/AMT/ESSD inter-journal SI)". It is not associated with a conference.

Acknowledgements. We want to express our gratitude to SPARC and WCRP (World Climate Research Programme) for their guidance, sponsorship, and support of the WAVAS-II program. Work at the Naval Research Laboratory was funded by NASA under the Upper Atmosphere Research Program and by the Office of Naval Research. The Atmospheric Chemistry Experiment (ACE), also known as SCISAT, is a Canadian-led mission mainly supported by the Canadian Space Agency and the Natural Sciences and Engineering Research Council of Canada. The WVMS measurements at Lauder are supported by Mike Kotkamp and the team at the NIWA Lauder atmospheric research facility. We would like to thank the European Space Agency (ESA) for making the MIPAS level-1b dataset available. SCIAMACHY spectral data were provided by ESA. The work on the SCIAMACHY water vapor data products was funded by DLR (German Aerospace Center) and the University of Bremen. The SCIAMACHY limb water vapor dataset v3.01 is a result of the DFG (German Research Council) Research Unit "Stratospheric Change and its Role for Climate Prediction" (SHARP) and the ESA SPIN (ESA SPARC Initiative) project; the data were partly calculated using the resources of the German HLRN (High-Performance Computer Center North). Odin is a Swedish-led satellite project funded jointly by the Swedish National Space Board (SNSB), the Canadian Space Agency (CSA), the National Technology Agency of Finland (Tekes), and the Centre National d'Etudes Spatiales (CNES) in France. The Swedish Space Corporation is the industrial prime constructor. Since April 2007, Odin has been a third-party mission of the ESA. We thank Hugh Pumphrey and an anonymous reviewer for their helpful comments.

Edited by: Stefan Buehler

Reviewed by: Hugh C. Pumphrey and one anonymous referee

\section{References}

Boone, C. D., Nassar, R., Walker, K. A., Rochon, Y., McLeod, S. D., Rinsland, C. P., and Bernath, P. F.: Retrievals for the Atmospheric Chemistry Experiment Fourier-Transform Spectrometer, Appl. Opt., 44, 7218-7231, 2005.

Boone, C. D., Walker, K. A., and Bernath, P. F.: Version 3 Retrievals for the Atmospheric Chemistry Experiment Fourier Transform Spectrometer (ACE-FTS), The Atmospheric Chemistry Experiment ACE at 10: A Solar Occultation Anthology, edited by: Bernath, P. F., A. Deepak Publishing, Hampton, Virginia, USA, 103-127, 2013.

Connor, B. J., Parrish, A., and Tsou, J. J.: Detection of stratospheric ozone trends by ground-based microwave observations, in: Remote Sensing of Atmospheric Chemistry, edited by: McElroy, J. L. and McNeal, R., Proc. SPIE Int. Soc. Opt. Eng., 1491, 218230, 1991.

DeWachter, E., Haefele, A., Kämpfer, N., Ka, S., Lee, J. E., and Oh, J. J.: The Seoul Water Vapour Radiometer for the Middle Atmosphere; Calibration, Retrieval and Validation, Transactions on Geoscience and Remote Sensing, 49, 1052-1062, https://doi.org/10.1109/TGRS.2010.2072932, 2011.

Deuber, B., Haefele, A., Feist, D. G., Martin, L., Kämpfer, N., Nedoluha, G. E., Yushkov, V., Khaykin, S., Kivi, R., and Vomel, H.: Middle Atmospheric Water Vapour Radiometer - MIAWARA: Validation and first results of the LAUTLOS / WAVVAP campaign, J. Geophys. Res., 110, D13306, https://doi.org/10.1029/2004JD005543, 2005.

Dinelli, B. M., Arnone, E., Brizzi, G., Carlotti, M., Castelli, E., Magnani, L., Papandrea, E., Prevedelli, M., and Ridolfi, M.: The MIPAS2D database of MIPAS/ENVISAT measurements retrieved with a multi-target 2-dimensional tomographic approach, Atmos. Meas. Tech., 3, 355-374, https://doi.org/10.5194/amt-3355-2010, 2010.

Forkman, P., Eriksson, P., and Winnberg, A.: The $22 \mathrm{GHz}$ radio-aeronomy receiver at Onsala Space Observatory, J. Quant. Spectrosc. Ra., 77, 23-42, https://doi.org/10.1016/S00224073(02)00073-0, 2003.

Gomez, R. M., Nedoluha, G. E., Neal, H. L., and McDermid, I. S.: The fourth-generation Water Vapor Millimeter-Wave Spectrometer, Radio Sci., 47, RS1010, https://doi.org/10.1029/2011RS004778, 2012.

Haefele, A., De Wachter, E., Hocke, K., Kampfer, N., Nedoluha, G. E., Gomez, R. M., Eriksson, P., Forkman, P., Lambert, A., and Schwartz, M. J.: Validation of ground-based microwave radiometers at $22 \mathrm{GHz}$ for stratospheric and mesospheric water vapor, J. Geophys. Res., 114, D23305, https://doi.org/10.1029/2009JD011997, 2009.

Hallgren, K. and Hartogh, P.: First detection of tidal behaviour in polar mesospheric water vapour by ground based microwave spectroscopy, Atmos. Chem. Phys., 12, 3753-3759, https://doi.org/10.5194/acp-12-3753-2012, 2012.

Hartogh, P. and Jarchow, C.: Groundbased detection of middle atmospheric water vapor, Global Process Monitoring and Remote Sensing of Ocean and Sea Ice, EUROPTO-Series 2586, 188 195, SPIE, Bellingham, 1995.

Hartmann, D. L., Klein Tank, A. M. G., Rusticucci, M., Alexander, L. V., Brönnimann, S., Charabi, Y., Dentener, F. J., Dlugokencky, E. J., Easterling, D. R., Kaplan, A., Soden, B. J., Thorne, P. W., Wild, M., and Zhai, P. M.: Observations: Atmosphere and 
Surface, in: Climate Change 2013: The Physical Science Basis. Contribution of Working Group I to the Fifth Assessment Report of the Intergovernmental Panel on Climate Change, edited by: Stocker, T. F., Qin, D., Plattner, G.-K., Tignor, M., Allen, S. K., Boschung, J., Nauels, A., Xia, Y., Bex, V., and Midgley, P. M., Cambridge University Press, Cambridge, United Kingdom and New York, NY, USA, 2013.

Hocke, K., Martin, L., and Kämpfer, N.: Survey of Intercomparisons of Water Vapour Measurements, in: Monitoring Atmospheric Water Vapour, Ground-based remote sensing and insitu methods, edited by: Kämpfer, N., ISSI Scientific Report 10, Springer Verlag, https://doi.org/10.1007/978-1-4614-3909-7, 2013.

Hurst, D. F., Read, W. G., Vömel, H., Selkirk, H. B., Rosenlof, K. H., Davis, S. M., Hall, E. G., Jordan, A. F., and Oltmans, S. J.: Recent divergences in stratospheric water vapor measurements by frost point hygrometers and the Aura Microwave Limb Sounder, Atmos. Meas. Tech., 9, 4447-4457, https://doi.org/10.5194/amt-9-4447-2016, 2016.

Kämpfer, N., Nedoluha, G., Haefele, A., and DeWachter, E.: Microwave Radiometry, in: Monitoring Atmospheric Water Vapour, Ground-based remote sensing and in-situ methods, edited by: Kämpfer, N., ISSI Scientific Report 10, Springer Verlag, https://doi.org/10.1007/978-1-4614-3909-7, 2013.

Kley, D., Russell, J. M., and Philips, C.: Stratospheric Processes and their Role in Climate (SPARC) - Assessment of upper tropospheric and stratospheric water vapour, SPARC Report 2, WMO/ICSU/IOCWorld Climate Research Programme, Geneva, 2000.

Lainer, M., Kämpfer, N., Tschanz, B., Nedoluha, G. E., Ka, S., and Oh, J. J.: Trajectory mapping of middle atmospheric water vapor by a mini network of NDACC instruments, Atmos. Chem. Phys., 15, 9711-9730, https://doi.org/10.5194/acp-159711-2015, 2015.

Le Texier, H., Solomon, S., and Garcia, R. R.: The role of molecular hydrogen and methane oxidation in the water vapor budget of the stratosphere, Q. J. Roy. Meteor. Soc., 114, 281-296, https://doi.org/10.1002/qj.49711448002, 1988.

Lossow, S., Urban, J., Eriksson, P., Murtagh, D., and Gumbel, J.: Critical parameters for the retrieval of mesospheric water vapour and temperature from Odin/SMR limb measurements at 557 GHz, Adv. Space Res., 40, 835-845, 2007.

Lossow, S., Khosrawi, F., Nedoluha, G. E., Azam, F., Bramstedt, K., Burrows, John, P., Dinelli, B. M., Eriksson, P., Espy, P. J., GarcíaComas, M., Gille, J. C., Kiefer, M., Noël, S., Raspollini, P., Read, W. G., Rosenlof, K. H., Rozanov, A., Sioris, C. E., Stiller, G. P., Walker, K. A., and Weigel, K.: The SPARC water vapour assessment II: comparison of annual, semi-annual and quasi-biennial variations in stratospheric and lower mesospheric water vapour observed from satellites, Atmos. Meas. Tech., 10, 1111-1137, https://doi.org/10.5194/amt-10-1111-2017, 2017.

Nedoluha, G. E., Bevilacqua, R. M., Gomez, R. M., Thacker, D. L., Waltman, W. B., and Pauls, T. A.: Ground-based measurements of water vapor in the middle atmosphere, J. Geophys. Res., 100, 2927-2939, 1995.

Nedoluha, G. E., Bevilacqua, R. M., Gomez, R. M., Waltman, W. B., Hicks, B. C., Thacker, D. L., Russell III, J. M., Abrams, M., Pumphrey, H. C., and Connor, B. J.: A comparative study of mesospheric water vapor measurements from the ground-based
Water Vapor Millimeter-wave Spectrometer and space-based instruments, J. Geophys. Res., 102, 16647-16661, 1997.

Nedoluha, G. E., Bevilacqua, R. M., Gomez, R. M., Siskind, D. E., Hicks, B. C., and Russell III, J. M.: Increases in middle atmospheric water vapor as observed by HALOE and the groundbased Water Vapor Millimeter-wave Spectrometer from 19911997, J. Geophys. Res., 103, 3531-3542, 1998.

Nedoluha, G. E., Bevilacqua, R. M., Gomez, R. M., Hicks, B. C., Russell III, J. M., and Connor, B. J.: An evaluation of trendsin middle atmospheric water vapor as measured by HALOE, WVMS, and POAM, J. Geophys. Res., 108, 4391, https://doi.org/10.1029/2002JD003332, 2003.

Nedoluha, G. E., Gomez, R. M., Hicks, B. C., Wrotny, J. E., Boone, C., and Lambert, A.: Water vapor measurements in the mesosphere from Mauna Loa over solar cycle 23, J. Geophys. Res., 114, D23303, https://doi.org/10.1029/2009JD012504, 2009.

Nedoluha, G. E., Gomez, R. M., Hicks, B. C., Helmboldt, J., Bevilacqua, R. M., and Lambert, A.: Ground-based microwave measurements of water vapor from the midstratosphere to the mesosphere, J. Geophys. Res.-Atmos., 116, D02309, https://doi.org/10.1029/2010JD014728, 2011.

Nedoluha, G. E., Gomez, R. M., Neal, H., Lambert, A., Hurst, D., Boone, C., and Stiller, G.: Validation of long-term measurements of water vapor from the midstratosphere to the mesosphere at two Network for the Detection of Atmospheric Composition Change sites, J. Geophys. Res.-Atmos., 118, 934-942, https://doi.org/10.1029/2012JD018900, 2013a.

Nedoluha, G. E., Michael Gomez, R., Allen, D. R., Lambert, A., Boone, C., and Stiller, G.: Variations in middle atmospheric water vapor from 2004 to 2013 , J. Geophys. Res.-Atmos., 118, 11285-11293, https://doi.org/10.1002/jgrd.50834, $2013 \mathrm{~b}$.

Payne, V. H., Noone, D., Dudhia, A., Piccolo, C. and Grainger, R. G.: Global satellite measurements of HDO and implications for understanding the transport of water vapour into the stratosphere, Q. J. Roy. Meteor. Soc., 133, 1459-1471, https://doi.org/10.1002/qj.127, 2007.

Raspollini, P., Carli, B., Carlotti, M., Ceccherini, S., Dehn, A., Dinelli, B. M., Dudhia, A., Flaud, J.-M., López-Puertas, M., Niro, F., Remedios, J. J., Ridolfi, M., Sembhi, H., Sgheri, L., and von Clarmann, T.: Ten years of MIPAS measurements with ESA Level 2 processor V6 - Part 1: Retrieval algorithm and diagnostics of the products, Atmos. Meas. Tech., 6, 2419-2439, https://doi.org/10.5194/amt-6-2419-2013, 2013.

Rodgers, C. D.: Retrieval of Atmospheric Temperature and Composition from Remote Measurements of Thermal Radiation, Rev. Geophys. Space Ge., 14, 609-624, 1976.

Scheiben, D., Schanz, A., Tschanz, B., and Kämpfer, N.: Diurnal variations in middle-atmospheric water vapor by ground-based microwave radiometry, Atmos. Chem. Phys., 13, 6877-6886, https://doi.org/10.5194/acp-13-6877-2013, 2013.

Stiller, G. P., Kiefer, M., Eckert, E., von Clarmann, T., Kellmann, S., García-Comas, M., Funke, B., Leblanc, T., Fetzer, E., Froidevaux, L., Gomez, M., Hall, E., Hurst, D., Jordan, A., Kämpfer, N., Lambert, A., McDermid, I. S., McGee, T., Miloshevich, L., Nedoluha, G., Read, W., Schneider, M., Schwartz, M., Straub, C., Toon, G., Twigg, L. W., Walker, K., and Whiteman, D. N.: Validation of MIPAS IMK/IAA temperature, water vapor, and ozone profiles with MOHAVE-2009 campaign measurements, 
Atmos. Meas. Tech., 5, 289-320, https://doi.org/10.5194/amt-5289-2012, 2012.

Straub, C., Tschanz, B., Hocke, K., Kämpfer, N., and Smith, A. K.: Transport of mesospheric $\mathrm{H}_{2} \mathrm{O}$ during and after the stratospheric sudden warming of January 2010: observation and simulation, Atmos. Chem. Phys., 12, 5413-5427, https://doi.org/10.5194/acp-12-5413-2012, 2012.

von Clarmann, T., Höpfner, M., Kellmann, S., Linden, A., Chauhan, S., Funke, B., Grabowski, U., Glatthor, N., Kiefer, M., Schieferdecker, T., Stiller, G. P., and Versick, S.: Retrieval of temperature, $\mathrm{H}_{2} \mathrm{O}, \mathrm{O}_{3}, \mathrm{HNO}_{3}, \mathrm{CH}_{4}, \mathrm{~N}_{2} \mathrm{O}, \mathrm{ClONO}_{2}$ and $\mathrm{ClO}$ from MIPAS reduced resolution nominal mode limb emission measurements, Atmos. Meas. Tech., 2, 159-175, https://doi.org/10.5194/amt-2159-2009, 2009.
Valeri, M., Barbara, F., Boone, C., Ceccherini, S., Gai, M., Maucher, G., Raspollini, P., Ridolfi, M., Sgheri, L., Wetzel, G., and Zoppetti, N.: $\mathrm{CCl}_{4}$ distribution derived from MIPAS ESA v7 data: intercomparisons, trend, and lifetime estimation, Atmos. Chem. Phys., 17, 10143-10162, https://doi.org/10.5194/acp-17-101432017, 2017.

Walker, K. A., et al.: The SPARC water vapour assessment II: Data set overview, in preparation, 2017.

Wrotny, J. E., Nedoluha, G. E., Boone, C., Stiller, G. P., and McCormack, J. P.: Total hydrogen budget of the equatorial upper stratosphere, J. Geophys. Res., 115, D04302, https://doi.org/10.1029/2009JD012135, 2010. 